\title{
Effect of glutamine on the nucleic acids exchange during the perioperative period in reconstructive oesophagus surgery
}

\begin{abstract}
Purpose: To assess the homeostasis of nucleic acids and nutritional status in the operation of one-stage esophagoplasty among patients diagnosed with achalasia of the esophagus or scar narrowing of esophagus after chemical burn.

Methods: The study included 37 patients from 20 to 65 years old, male and female with achalasia of the esophagus or scar narrowing of the esophagus after chemical burn. All patients underwent one-stage esophagectomy wuth the following plastic. In the first group, patients received standard preoperative preparation (preoperative and postoperative enteral nutritional support by izokaloric mixture). Enteral mixture with increased concentration of glutamine $(6 \mathrm{~g} / 100 \mathrm{ml})$ was added to a standard enteral mixture in patients of the second group (15) counting glutamine as $0.5 \mathrm{~g} / \mathrm{kg} /$ day (during three days before and two days after the surgery).

DNA concentration of blood plasma and uric acid concentration in urine were counted for the assessment of nucleic acids metabolism. General clinical indicators were examined to assess the nutritional status (total serum protein and albumin, transferrin, the absolute number of blood lymphocytes).

Results: The initial alimentary nutritional deficiency is exacerbated in the postoperative period because of development of the catabolism syndrome. We examined DNA concentration of serum and excretion of uric acid in the urine to assess the severity of nutritional deficiency, as one of the markers of nucleic acid homeostasis. Analyzing the results of the first group of patients, we saw a deep serum oligonucleotides deficiency in all phases of the perioperative period. Application of enteral mixture with glutamine in patients of the second group significantly improves exchange of nucleic acids and nutritional status.

Conclusion: There were revealed the dependence of the homeostasis state of nucleic acids and nutritional status. Patients in the first group had had two postoperative complications $(9.1 \%)$, in the second group there were no complications.
\end{abstract}

Keywords: esophagus achalasia, scar narrowing of the esophagus after chemical burn, nutritional support, nucleic acids exchange, glutamine
Volume 2 Issue 4 - 2015

\author{
Peshkova IV,' Bogachev SS, ${ }^{2}$ Drobyazgin EA,' \\ Chikinev YV,' Mitrofanov IM, ${ }^{3}$ Piontkovskaya \\ $\mathrm{KA},{ }^{2}$ Vereschagin $\mathrm{El}^{\prime}$ \\ 'State Medical University, Russia \\ ${ }^{2}$ Institute of Cytology and Genetics, Russia \\ ${ }^{3}$ Center of Clinical and Experimental Medicine, Russia
}

Correspondence: Eugene IVereshchagin, Head of the Department of Anesthesiology and Intensive Care, State Medical University, 63009I, Krasny Prospekt 52, Novosibirsk, Russia, Tel +79134583327, Email eivv1961@gmail.com

Received: December 19,2014 | Published: September 9, 2015

\section{Introduction}

Esophageal reconstructive surgery is one of the most traumatic and complicated one for anesthesiology and resuscitation support. The case of that complexity is not only in specificity of surgery, and in initial condition of the patient, particularly in initial nutritional deficiency of different stages against the background of alimentary deficiency of nutrients. According to traumatism and latitude of the one-stage esophageal reconstruction in its benign diseases in postoperative period, it is related to development of hypercatabolism syndrome and aggravation of current protein-energy balance. ${ }^{1-4}$

Burden in organs with rapidly dividing cells (hepatocytes, enterocytes, bone marrow cells) increases in many times with the development of critical situations, while the body is experiencing an obvious deficiency of energy on the background of intoxication and disturbances of gas exchange, which leads, in particular, and to a deficiency of nucleic acids synthesis. ${ }^{5-9}$ Reconstructive surgery in esophagus is not exclusion from that rule. It is obvious that in these patients and rate of division and cell viability depends on the intensity of nucleic acid metabolism, and this circumstance may determine the outcome and postoperative period..$^{5,9,10}$

Furthermore, synthesis of nucleotides in the body must be rapidly increased for cell division of intestine, bone marrow, liver, and the amino acid glutamine can provide that, -one of the main substrates for the synthesis of purines and pyrimidines. ${ }^{10,11}$ Because glutamine is the main donor of amino groups for the synthesis of nucleotides, its use for correcting their deficits and normalization of nucleic acid homeostasis becomes pathogenesis based technology.

It should be noted that according to J Wernerman et al., ${ }^{8}$ glutamine is replaceable, but the most common free amino acid. The highest concentration of glutamine in the muscles is determined $(20 \mathrm{mmol} / 1$ of the concentration of all 30 amino acids mmol/l) and besides, high glutamine concentration is characteristically for intestinal mucosa , liver, and leukocytes. Under conditions of stress glutamine is 
becoming a major energy substrate for rapidly dividing cells and begins being actively consumed, so that reduces the concentration of glutamine in muscles. Reducing of glutamine after surgery (normalizing to the 20th day) is correlated with decreasing amount of polyribosomes in muscles, which are not fully restored even to the 30th day, and that leads to a extremely slow recovery of nucleotide and protein synthesis. ${ }^{8}$ Taking into account these mechanisms, the use of enteral mixture with a high content of glutamine in the perioperative period in reconstructive interventions on the esophagus becomes pathogenesis based technology, which on the one hand restores the original nutritional deficiency of oligonucleotides, and with another - satisfies an increased need for glutamine on the background of postoperative stress. Thus, the above identified problems caused the study of nucleic acid homeostasis and their correction by introducing a scheme of perioperative nutritional support with mixtures containing glutamine $(6 \mathrm{~g} / 100 \mathrm{ml}$ enteral mixture, Intestamin) in addition to a standard enteral nutrition.

\section{Materials and methods}

The study included 37 patients from 20 to 65years old, male and female, diagnosed with achalasia of the esophagus and scar narrowing (SNE and AE) of the esophagus after chemical burn. All patients underwent surgery in the volume of video assisted extirpation of the esophagus, plastic of esophagus with stomach tube in the clinic of hospital surgery of State Medical University (Novosibirsk, RF). This study was approved by the ethics committee of the Novosibirsk State Regional Hospital (protocol number 24, dated 22.10.2007). Inclusion criteria: patients with SNE or AE III-IV, requiring reconstructive surgical treatment-esophagoplasty; presence high epidural block in complex anesthetic and resuscitation supplement; operated in the age from 18 to 65 years. Exclusion criteria: esophageal cancer or detecting it according to postoperative pathologic study removal of the esophagus; chronic viral hepatitis; tuberculosis; severe comorbidities (circulatory insufficiency III, chronic renal failure III-IV, diabetes mellitus (DM) of the first type, for heavy, chronic liver failure ); patient refusal to participate in the study.

The first group included 22patients who received standard preoperative preparation (preoperative and postoperative nutritional support with the usual enteric mixture). Patients of the second group (15 men) in addition to the standard enteral mixture received enteral mixture, as the perioperative nutritional support, with a high content of glutamine $30 \mathrm{~g} / 500 \mathrm{ml}$ (Intestamin), the amount of glutamine was $0.5 \mathrm{~g} / \mathrm{kg} /$ day $(500 \mathrm{ml} /$ day of Intestamin for three days before and two days after the surgery). Starting amounts of protein and energy were determined from the physiological needs- $1 \mathrm{~g} / \mathrm{kg} /$ day and $25 \mathrm{kcal} / \mathrm{kg} /$ day, respectively, then they were recalculated through the nitrogen excretion in the urine in accordance with the needs of a particular patient. All patients had introduced nasogastric tube for nutrition. Preoperative nutritional support lasted 7-10days. Targets were established as:- albumin levels $>35 \mathrm{~g} / 1$, serum total protein $(>65 \mathrm{~g} / \mathrm{l})$, the absolute number of lymphocytes $(>1500 * 109 / 1)$.

Control over the course of perioperative support quality in addition to standard general clinical indicators was carried out by the level of the absolute number of lymphocytes (ANL), transferrin concentration and blood plasma DNA, and daily excretion of urea nitrogen and uric acid of urine in the perioperative period (baseline, $1^{\text {st }}, 3^{\text {rd }}$ and $7^{\text {th }}$ day). DNA levels in the blood plasma were evaluated by Shmidt - Tangauzer method (separation of RNA and DNA by hydrolysis of the investigated material allowing to weak alkali to isolate DNA as a precipitate, followed by quantitative determination). Measurements were made at 270 and $290 \mathrm{~nm}$ on a spectrophotometer «Genesys 10uv», «Thermo Spectronic», Germany. The level of urea and uric acid in the daily urine, serum albumin were determined by biochemical analyzer «AU- 480» of the company Beckman Coulter, Inc. (UK) using kits firm Biocon (Germany), standard calibration solutions Biocon (Germany) and Roshe System (Switzerland) as the method of endpoint. Absolute lymphocyte counting was held on automatic hematology analyzer «Sysmex XT-2000i», company «Hoffman La Roche» (Switzerland) on the basis of flow cytometry. The study was conducted in accordance with the ethical standards and standards adopted in RF. Data processing was held by software package Statistica 7.0.

\section{Results and discussion}

We identified DNA concentration of blood plasma in all stages of the perioperative period (Table 1) to assess the nucleic acid metabolism in 37 patients from 20 to 65years old, male and female, diagnosed with achalasia of the esophagus and scar narrowing of the esophagus after chemical burn.

The data showed all patients starting deep deficiency of DNA content in blood plasma. No correlations between serum nucleotides content and age, sex of patients were noted. Patients in the first group, in spite of an active nutritional support before and after the surgery, had no significant changes in the level of nucleic acids in blood plasma. Patients of the second group after administration of the standard nutritional support scheme of Intestamin in the dose of $500 \mathrm{ml} /$ day $(0.3-0.5 \mathrm{~g} / \mathrm{kg} /$ day of glutamine) had had DNA concentration in the blood plasma before the surgery increased in ten times (Table 1).

We determined the main product of the metabolism of purine nucleotides to evaluate the intensity of the nucleic acid metabolism daily excretion of uric acid in the urine (Table 2).

It that at the first group of patients lowest level of daily urinary uric acid excretion was established to be before surgery and on the third postoperative day. Presumably, it was related to the break of nucleic acids exchange. The second group was examined at the background of enriching food by glutamine, and dynamics of daily excretion of uric acid urine indicated an increase in the intensity of the nucleic acid metabolism: excretion increased almost twice $(p<0.0001)$. Against the background of a persistent increasing in the level of DNA in the blood plasma of the daily value of urinary excretion of uric acid didn't overcome the physiological values, and that confirms the active usage of nucleotides in reparative processes. The daily excretion of uric acid was directly correlated with the level of DNA in blood plasma $(r=0,84 ; p<0,01)$. Furthermore, deficiency of nucleotides (low DNA in the blood) was closely correlated with the absolute number of lymphocytes (ANL) in different stages of a perioperative period $(r=0,57-0,68 ; p<0,001)$. ANL in patients of the second group in the first postoperative day remained in the normal range and was significantly higher than in the first group of patients, who were fed with the standard preoperative enteral mixture (Table 3 ).

Transferrin concentration was also higher in the second group at days 3 and $7(p<0,05$; Table 3$)$. Direct correlation was registered between content of DNA and transferrin in blood plasma: Spearman correlation coefficient (r) was between 0.52 to 0.77 depending on the stage of the study $(p<0,05)$. Thus, the analysis of the initial nutritional status of patients and the SNE and AE showed that visceral protein pool was keeping stored: 
values of total protein, albumin, ACL were in the range of normative values. But when considering indicators such as transferrin and blood plasma DNA we obtained a different picture: typical lack of transferrin and a very low concentration of blood plasma DNA.

Table I Dynamics of DNA concentration in blood plasma $(\mathrm{ng} / \mathrm{ml})$ in the perioperative period'

\begin{tabular}{lll}
\hline Study stages & $\begin{array}{l}\text { Group I } \\
(\mathbf{n = 2 2})\end{array}$ & $\begin{array}{l}\text { Group 2 } \\
(\mathbf{n}=15)\end{array}$ \\
\hline Initially & $0.50 \pm 0.10$ & $0.97 \pm 0.06$ \\
Before the surgery & $0.56 \pm 0.13$ & $84.24 \pm 6.49 * \#$ \\
The $I^{\text {st }}$ day after the surgery & $1.03 \pm 0.15$ & $67.55 \pm 4.86^{* \#}$ \\
The $3^{\text {rd }}$ day after the surgery & $1.13 \pm 0.18$ & $72.37 \pm 4.95 * \#$ \\
The $7^{\text {th }}$ day after the surgery & $0.82 \pm 0.24$ & $84.51 \pm 2.50^{* \#}$
\end{tabular}

$* P<0.000$ I comparing the dynamics of the DNA concentration in the 2 nd group (criterion of Friedman); $\#-P<0.000$ I comparing Ist and 2 nd groups (criterion of Mann-Whitney. I for conventional norm accepted indicator of DNA concentration in the blood plasma of healthy donors, which for this method is $25-65 \mathrm{ng} / \mathrm{ml}$

Table 2 Dynamics of urinary excretion of uric acid (mmol///day) in the perioperative period

\begin{tabular}{lll}
\hline Test & $\begin{array}{l}\text { Group I } \\
(\mathbf{n = 2 2})\end{array}$ & $\begin{array}{l}\text { Group 2 } \\
(\mathbf{n = 1 5 )}\end{array}$ \\
\hline Before the surgery & $1.6 \pm 0.24$ & $3.22 \pm 0.22^{*}$ \\
3days after the surgery & $1.8 \pm 0.21$ & $3.44 \pm 0.24^{*}$ \\
7days after the surgery & $2.01 \pm 0.19$ & $3.5 \pm 0.18^{*}$ \\
\hline
\end{tabular}

$* \mathrm{P}<0.000 \mathrm{I}$ comparing Ist and 2 nd groups (criterion of Mann-Whitney test); regulatory uric acid excretion rate is I.5-4.5mmol/I/day

Table 3 Evolution of the absolute number of lymphocytes and transferrin in the perioperative period

\begin{tabular}{lllll}
\hline & \multicolumn{2}{c}{ Absolute number of leucocytes $\left(* 10^{9} / \mathrm{I}\right)$} & \multicolumn{2}{c}{ Transferrin $(\mathrm{g} / \mathrm{l})$} \\
\cline { 2 - 4 } & Group I & Group 2 & Group I & Group 2 \\
\hline Initially & $2.09 \pm 0.12$ & $2.1 \pm 0.11$ & $1.5 \pm 0.11$ & $1.6 \pm 0.15$ \\
Before the surgery & $2.18 \pm 0.14$ & $2.33 \pm 0.18$ & $1.5 \pm 0.15$ & $2.0 \pm 0.21$ \\
The $1^{\text {st }}$ day & $0.93 \pm 0.11$ & $1.08 \pm 0.14$ & $1.07 \pm 0.11$ & $1.2 \pm 0.2$ \\
The $3^{\text {rd }}$ day & $1.2 \pm 0.1$ & $1.56 \pm 0.15 \#$ & $1.15 \pm 0.1$ & $2.01 \pm 0.2^{*}$ \\
The $7^{\text {th }}$ day & $1.73 \pm 0.15$ & $1.83 \pm 0.16$ & $1.28 \pm 0.12$ & $2.21 \pm 0.1 *$ \\
\hline
\end{tabular}

$\# p<0,00$ I if compared with the Group I; ${ }^{*} \mathrm{p}<0,05$ if compared with initial level

When considering the number of complications in patients of the first group it was registered two: esophagoggastroanastomosis leak at the neck and pneumonia. There were no complications in the patients of the second group. Furthermore, there was significant reduction in patient length of stay in the intensive care unit in the second group: $5.5 \pm 0.56$ in the first group vs $4.2 \pm 0.26$ in the second $(\mathrm{p}<0.001)$.

There were almost no attention to disturbances of nucleic acid metabolism in intensive care, despite the priority role in protein, carbohydrate and lipid metabolism. It may be noted, that small number of publications has mostly experimental character, devoted to excessive production of oligonucleotides in septic shock. ${ }^{12,6}$

However disturbance of nucleic acid synthesis de novo may be assumed in patients with nutritional deficiency in the perioperative period. Consequences of nucleic acid synthesis depretion (both RNA and DNA) may be very different. In the perioperative period decreasing in the rate of cell division barrier organs (liver, intestine) and bone marrow might be the most dangerous. The paradox is that the rate of cell division in the progression of critical state must be increased. Thus, simple calculation shows that the rate of cell division of the bone marrow for systemic inflammatory response may increase in the tens or even hundreds of times. Therefore, disturbance of the synthesis of nucleic acids is accompanied by multiple organ dysfunction, prolonged catabolic period, high risk of infectious complications. Furthermore, disruption of the nucleic acid synthesis can be accompanied by decrease in tissue repair with potential complications, such as anastomosis leak, etc.

That is why the analysis of nucleic acid metabolism disorders in surgery and intensive care is important. With that purpose we used two direct and two indirect indicators. The first indicators included oligonucleotides (DNA) in blood plasma and the daily urinary excretion of uric acid. We have assigned ANL and serum transferrin to the second (indirect) indicators.

Normally, as it was previously shown by us, SN Tamkovich et $\mathrm{al}$, and SA Leon, B. Shapiro, level of oligonucleotides is 1.8-65ng/ ml. ${ }^{1,5,12,13}$ Exceeding more than $100 \mathrm{ng} / \mathrm{ml}$ is observed in purulentseptic diseases, septic shock, severe trauma. These conditions 
increase the serum concentration of the nucleotides via the release of the nucleic acids of dying cells and bacteria. Previously it has been shown that large quantities of oligonucleotides can be activators of SIRS. ${ }^{6}$ However, there were no publications about conditions, accompanied by a reduced concentration of nucleic acids in blood plasma of patients in the perioperative period.

We have shown that all patients with a diagnosis of cicatricial contracture after chemical burn or achalasia of the esophagus in the preoperative period have decreased nucleic acids in blood plasma, there were a direct correlations between concentration of nucleic acids in blood plasma and amount of lymphocytes, concentration of transferrin and daily excretion of uric acid in the urine. However, the correlations with Ketle index, concentration of albumin and total protein were nonsignificant. It is interesting, that there is quite prominent negative correlation between underweight patients (\%) and the concentration of DNA on the first and third postoperative day $(\mathrm{r}=-$ $0,43-0,46 ; p<0,05)$, i.e., the more the initial weight deficiency in a patient, the lower the concentration of DNA is expected on the first and the third postoperative day. These data indicate more profound deficiency of nucleotides in patients with significant deficits in weight, and hence deeper disorder of nucleic acids homeostasis. Thus, the low level of nucleic acids of blood plasma is the same as the reliable indicator of nutritional status, as transferrin and ACL.

Daily urinary excretion of uric acid was selected to evaluate the intensity of nucleic acid metabolism as a final degradation product of purine nucleotides. Daily excretion of uric acid in the urine can be used for direct estimation of nucleic acids metabolism, and possibly of their deficit, since there is a direct correlation with the level of DNA in blood plasma $(r=0.84 ; \mathrm{p}<0.01)$. It is necessary to take into account, that the isolated evaluation of DNA concentration in the blood is not sufficient for diagnosis of nucleic acid metabolism disturbances, because in catabolism conditions and with massive destruction of tissue debris DNA circulation is possible within the normative values in the blood. The daily excretion of uric acid in the urine remained below normal and indicated the low intensity of nucleotide synthesis de novo with deficiency of substrates. Thus, the estimation of daily excretion of uric acid in the urine and serum levels of nucleic acids can accurately assess the intensity of nucleic acid metabolism. In our study, decrease excretion of uric acid was noted in all patients with impaired nutritional status, and in some cases decreased formation of uric acid in 3-4 times was observed in comparison with normal creatinine clearance. It shows deep damages of nucleic acid metabolism. It is obvious that decreasing of exchange of the nucleic acids affects the reduction of uric acid production. Moreover, the evaluation of the correlation coefficient Spearman confirms the validity of this conclusion: the dependence of the initial level of the absolute number of lymphocytes $(r=0.68)$ was noted with high significance $(\mathrm{p}<0.01)$. Transferrin level $(\mathrm{r}=0.77)$, albumin ( $\mathrm{r}=0.44)$ and urine uric acid excretion $(\mathrm{r}=0.84)$ were correlated with the initial DNA concentration as well. It seems that the level of transferrin and ANL are not only indicators of common nutritional deficiency, but also indirect indicators of failure of nucleic acid metabolism due to the high correlation with direct indicators - concentration of oligonucleotides in blood plasma and urinary uric acid.

Very few studies are devoted to reactivators of nucleic acid synthesis, particularly in intensive therapy. It is known that one of the key substances in the synthesis of nucleic acids is glutamine..$^{14,15}$ Energetical utilization of glutamine is profitable because its oxidation in the Krebs cycle provides almost as much energy of ATP, as oxidation of glucose: $30 \mathrm{mmol}$ of ATP from $1 \mathrm{~mol}$ of glutamine (one mole of glucose yields $36 \mathrm{mmol}$ of ATP). That is why the deep deficit of glutamine is rapidly developing in the initial conditions of nutritional deficiency in patients in the postoperative period, which has a negative impact on the homeostasis of nucleic acids: the initial lack of nucleotides is exacerbated because of building of new nucleic acids. Under these circumstances we used a mixture of enteric mixture with the high content of glutamine $(6 \mathrm{~g} / 100 \mathrm{ml})$ to restore nucleic acid metabolism in the perioperative period. Thus, Wernerman J et al., ${ }^{11}$ showed participation of glutamine in synthesis of nucleic acids de novo. According to this group of Scandinavian investigators synthesis of nucleic acids increases in hundreds times or more at sufficient concentration of glutamine. We had previously shown significant increasing of DNA in blood plasma and daily excretion of uric acid in the urine of patients with preoperative using of glutamine. ${ }^{5}$ In the present study, we cover the whole perioperative period: the use of glutamine tenfold increases the oligonucleotides concentration in blood plasma. The daily excretion of uric acid in the urine was also significantly increased.

Such changes are not caused by catabolism and worsening of disaster, since all known indicators of nutritional status (transferrin, ANL, albumin) had positive changes. Using such pharmaconutrition as glutamine significantly accelerates recovery of transferrin concentration and the absolute number of lymphocytes (Table 3). The concentration of transferrin becomes higher than baseline values and ANL began to grow on the $3^{\text {rd }}$ postoperative day. This important fact points to the dependence of rapidly dividing cells of the immune system on sufficient number of nucleotides to produce them. Ultimately, direct and indirect indicators of nucleic acid metabolism were within normal limits in patients with inclusion of glutamine in the program of preoperative preparation and during the perioperative period.

It should be noted that the "extreme" lymphopenia in postoperative period of major surgery may serve, on the one hand, as the predictor of severe postoperative complications, and on the other, to serve as the basis for inclusion of high doses of glutamine in the protocol of postoperative therapy for the correction of nucleic acid metabolism.

\section{Conclusion}

i. Patients with esophagus achalasia and esophageal scar narrowing after chemical burn have the deficiency of the plasma concentrations of nucleotides and decreased daily excretion of uric acid urine during the perioperative period.

ii. DNA Concentration in blood plasma and the uric acid in the urine may be additional markers of nutritional deficiency severity in patients with malnutrition.

iii. Pharmaconutrition with glutamine intensifies exchange of nucleotides that makes use of enteral mixture with the high concentration of glutamine pathogenetically substantial technology in reactivation of nucleic acid synthesis in the perioperative period.

iv. Concentration of DNA in blood plasma below $10 \mathrm{ng} / \mathrm{ml}$, the initial deficit of transferrin and the development of absolute lymphopenia below $1.0 * 109 / \mathrm{L}$ in the postoperative period show the decline in the synthesis of nucleic acids and can serve as a basis of glutamine inclusion into the program of nutritional support, to correct homeostasis of nucleic acids and improve the nutritional status of patients with reconstructive operations on the esophagus 


\section{Acknowledgments}

The authors would like to thank Prof. Paul van Leeuwen (Department of Surgery VU University Medical Center, Amsterdam, the Netherlands) for support and assistance.

\section{Conflict of interest}

Author declares that there is no conflict of interest.

\section{References}

1. Berkasova IV, Vereshchagin EI Chikinev Y, et al. Nutritional support: essential component of preoperative preparation for surgery of the esophagus. European Pubmed Central. 2012;171(5):65-68.

2. Sobotka L. Fundamentals of Clinical Nutrition: Proceedings of the lecture courses of the European Association for Parenteral and Enteral nutrition: tr. with Engl. Petrozavodsk: INTELTEC; 2003:416.

3. Braga M, Gianotti L, Vignali A, et al. Artificial nutrition after major abdominal surgery: impact of route of administration and composition of diet. Crit Care Med. 1998;26(1):24-30.

4. Weimanna A, Braga M, Harsanyic L, et al. ESPEN Guidelines on Enteral Nutrition: Surgery including Organ Transplantations. Clin Nutr. 2006;25(2):224-244.

5. Berkasova IV, Vereshchagin EI, Valeyeva VA, et al. Correction of nucleic acid metabolism in the perioperative period in patients with benign esophageal diseases. Electronic Journal Science and Education in Siberia. 2012:6.
6. Adjei AA, Yamamoto S. A dietary nucleoside-nucleotide mixture inhibits endotoxin-induced bacterial translocation in mice fed proteinfree diet. $J$ Nutr. 1995;125(1):42-48.

7. Carver JD. Dietary nucleotides: effects on the immune and gastrointestinal systems. Acta Paediatr Suppl. 1999;88(430):83-88.

8. Luo JL, Hammarqvist F, Andersson K, et al. Surgical trauma decreases glutathione synthetic capacity in human skeletal muscle tissue. Am J Physiol. 1998;275(1 Pt 1):E359-E365.

9. Rodas PC, Rooyackers O, Hebert C, et al. Glutamine and glutathione at ICU admission in relation to outcome. Clin Sci (Lond). 2012;122(12):591-597.

10. Wernerman J, Kirketeig T, Andersson B, et al. Scandinavian glutamine trial: a pragmatic multi-centre randomised clinical trial of intensive care unit patients. Acta Anaesthesiol Scand. 2011;55(7):812-818.

11. Wernerman J. Glutamine supplementation. 2011;1:25

12. Tamkovich SN, Vlasov VV, Laktionov PP. Circulating deoxyribonucleic acids in blood and their using in medical diagnostics. Mol Biol (MOSK). 2008;42(1):12-23.

13. Leon SA, Shapiro B, Sklaroff DM, et al. Free DNA in the serum of cancer patients and the effect of therapy. Cancer Res. 1977;37(3):646-650.

14. Wernerman J. Clinical use of glutamine supplementation. J Nutr. 2008;138(10):2040S-2044S

15. Vlasov VV, Laktionov PP, Rykova EY. Extracellular nucleic acids. Bioessays. 2007;29(7):654-667. 